\title{
Prevalenza dei genotipi di HCV nella Sicilia centro-meridionale
}

\author{
Liborio Bellomo, Irene Maria Miraglia \\ Servizio di Virologia-Azienda Ospedaliera S. Elia di Caltanissetta \\ Prevalence of HCV genotypes in centre-southern Sicily
}

Key Words: HCV, Genotype

\section{SUMMARY}

In this issue the prevalence of HCV genotypes was: $60.3 \%$ for Ib; $13.9 \%$ for $3 \mathrm{a} ; 10.9 \%$ for $1 \mathrm{a}$; $10.4 \%$ for $2 \mathrm{a}$ or $2 \mathrm{c}$; $3.5 \%$ for $4 \mathrm{c}$ or $4 \mathrm{~d}$. The genotypes $\mathrm{Ib}, 3 \mathrm{a}$, Ia and $4 \mathrm{c}$ or $4 \mathrm{~d}$ are more frequent in males, while $2 \mathrm{a}$ or $2 \mathrm{c}$ have a more equalized distribution in females and males. Two female patients with an infection of $\mathrm{Ia}+\mathrm{Ib}$ genotypes were observed.

\section{INTRODUZIONE}

Il virus dell'epatite $\mathrm{C}$ (HCV) è il principale responsabile di epatiti post-trasfusionali.

Sfortunatamente in circa il 50\% dei casi la malattia tende a cronicizzate. I test sierologici classici presentano limiti diagnostici sia nella fase acuta della malattia che nel suo decorso, mentre la tecnica Polimerase Chain Reaction (PCR), amplificando il materiale genetico virale, permette di individuare la presenza del virus. L'identificazione del genotipo virale e la quantizzazione della viremia forniscono uno strumento diagnostico prezioso ai fini dell'impostazione terapeutica e del suo monitoraggio (2). Le odierne metodologie analitiche hanno consentito di introdurre lo studio relativo alla presenza del virus in altri fluidi biologici, quali ad esempio il liquido seminale (1), nonché di monitorare $(3,5)$ e comparare gli effetti di associazioni farmacologiche $(4,6)$. Secondo Squarcione et al., dalle schede di notifica individuale delle epatiti inviate al Ministero della Salute si evince che la prevalenza della epatite $\mathrm{C}$ è più significativa nel Centro-Sud della penisola, pertanto è stato condotto uno studio epidemiologico descrittivo con la precisa finalità di stabilire l'esatta prevalenza dei vari genotipi del virus dell'epatite $\mathrm{C}(\mathrm{HCV})$ e di eventuali infezioni miste nella popolazione della Sicilia centro-meridionale che afferisce al nostro centro.

\section{Pazienti e metodologia}

Questa indagine ha preso in esame 202 pazienti che sono venuti alla nostra osservazione dalla seconda metà del 2000 alla fine del 2001. Sono stati studiati sia soggetti candidati alla terapia antivirale o portatori di epatopatia più o meno pronunciata, ma anche alcuni pazienti apparentemente in buona salute, naturalmente positivi alla ricerca di anticorpi anti $\mathrm{HCV}$ con metodica immunoenzimatica. Il test analitico utilizzato è il "Genotype HCV III" della Nuclear Laser Medicine basato su un'ibridazione inversa su striscia di un amplificato ottenuto con la metodologia PCR che consente l'identificazione dei 7 maggiori tipi e dei sottotipi più comuni di HCV.

\section{RISULTATI}

I 202 pazienti sono stati catalogati nel seguente modo (tabella 1, 2):

- Genotipo 1b 60.3\% (62\% di sesso maschile e $38 \%$ di sesso femminile);

- Genotipo 3a 13.9\% (89\% di sesso maschile e 11 $\%$ di sesso femminile);

- Genotipo 1a 10.9\% (82\% di sesso maschile e $18 \%$ di sesso femminile);

- Genotipo 2a or 2c 10.4\% (57\% di sesso maschile e $43 \%$ di sesso femminile);

- Genotipo 4c or 4d 3.5\% (71\% di sesso maschile e $29 \%$ di sesso femminile);

- Genotipo $1 \mathrm{a}+1 \mathrm{~b}$ 1\% (100\% di sesso femminile).

\section{DISCUSSIONE}

Il genotipo più spesso coinvolto è l'1 (segnatamente $60.3 \% 1 \mathrm{~b}, 10.9 \% 1 \mathrm{a}$ ed $1 \% 1 \mathrm{a}+1 \mathrm{~b}$ ), segue a notevole distanza il 3a; i sottotipi 1a ed $2 \mathrm{a}$ or $2 \mathrm{c}$ all'incirca si equivalgono, mentre il meno diffuso nella nostra realtà è il sottotipo $4 \mathrm{c}$ or $4 \mathrm{~d}$. I casi di confezione sfiorano $1 ' 1 \%$. Analizzando i dati in relazione al sesso dei pazienti si osserva che alcuni genotipi prediligono in misura assai preminente il sesso maschile (3a- 1a- $4 c$ or $4 d$ ). Il $2 a$ or $2 c$ ha invece una distribuzione più equilibrata fra $\mathrm{i}$ due sessi. I 2 casi di confezione sono state evidenziati in pazienti di sesso femminile. 
Tabella I. Distribuzione percentuale genotipi HCV

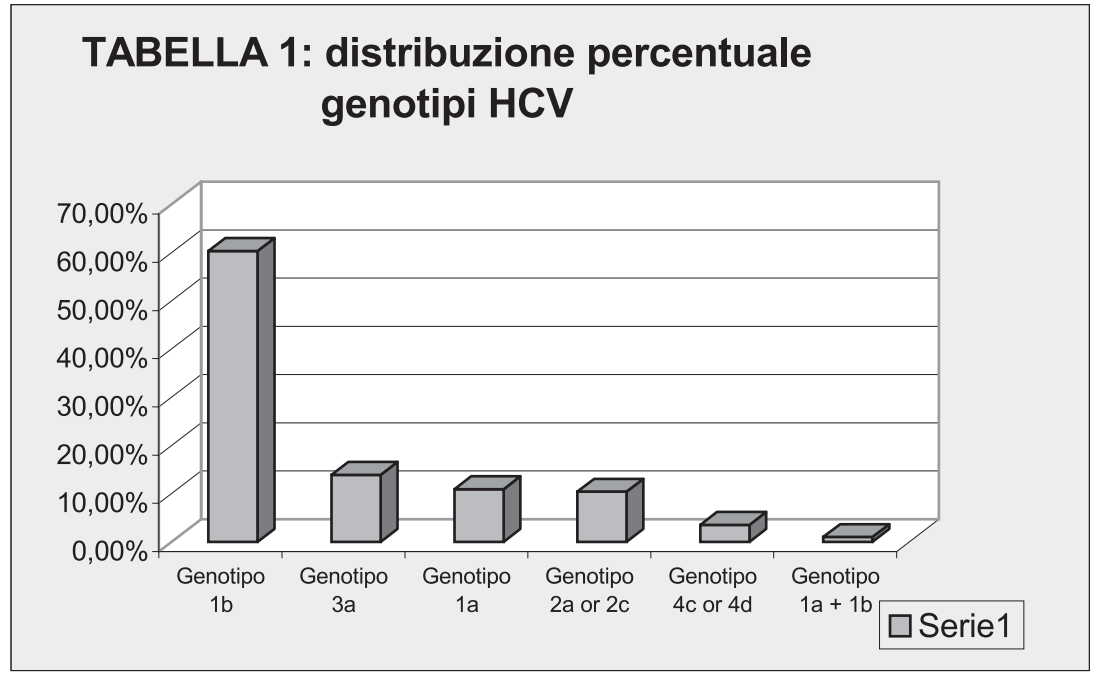

Tabella 2. Distribuzione secondo sesso dei genotipi HCV

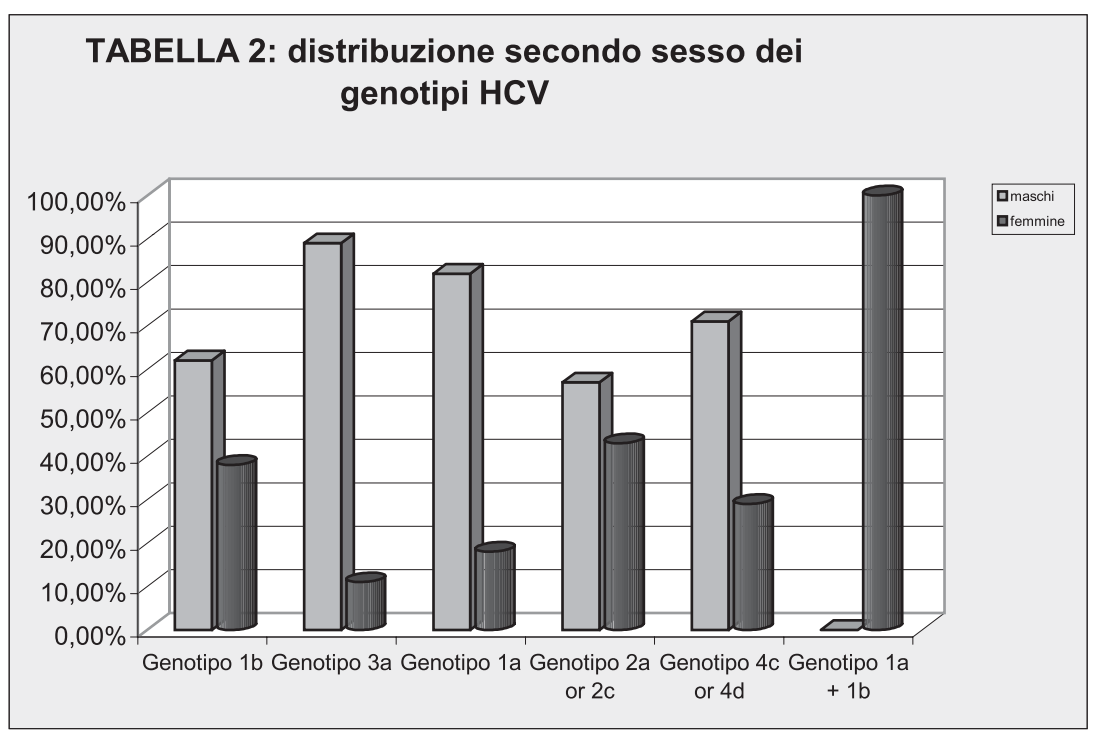

\section{BIBLIOGRAFIA}

1. Dore GJ, Kaldor JM, et al. Detection of HCV-RNA in semem. Lancet 2000; 356: 1520

2. Dubois F, Desencios J, Mariotte N, Goudeau A. Hepatitis C in a french population-based Survey, 1994: sieroprevalence, frequency of viremia, genotype distribution and risk factor. Hepatology 1997; 25: 1490-6.

3. Fontaine H, Nalpas B, et al. Effect of pregnancy on chronic hepatitis $\mathrm{C}$ : a case control study. Lancet 2000; 356: 1328-9.

4. Frenci $\mathrm{P}$, Brunner $\mathrm{H}$, et al. Combination of interferon induction therapy and ribavirin in chronic hepatitis C. Hepatology 2001; 34: 1006-11.

5. Lake G, Bakaar G, Jessner W, et al. Primary infection resistance and treatment response in chronic hepatitis C infection. Lancet 2002; 359: 1064-5.

6. Pol S, Nalpas B, et al. Combination of ribavirina and interferon-alfa surpasses high doses of interferon-alfa alone in patients with genotype-1b-related chronic hepatitis C. Hepatology 2000; 31: 1338-44.

\section{Liborio Bellomo}

Servizio di Virologia

Azienda Ospedaliera S. Elia

Via L. Russo 6;

93100 Caltanissetta

Tel/Fax 093 4559555;

e-mail: liboriobellomo@virgilio.it 